\title{
Bloodlust of Wildlife Fishing and Hunting Quenched by Industrial Agricultural Engineering
}

\author{
Louis ZG Touyz* \\ Faculty of Dentistry, McGill University, Canada \\ *Corresponding author: Louis ZG Touyz, Faculty of Dentistry, McGill University, Canada.
}

Submission: 海 July 01, 2018; Published: 㭗July 13, 2018

\begin{abstract}
The history of food production and its preservation is reviewed. The supply of food demand from global populations is discussed. Focus is drawn on animal factory farms and plant sources of protein for humans. Nutrition derived from vegetarian and carnivore diets are appraised.Motivation psychology and mindsets of hunters and fishers are deconstructed and gratuitous killing of wild animals is deplored. The irreversible damage to wild life fauna and to aquatic fish-stock destruction, wrought by fishers and hunters respectively, is underlined. Sound food sources exist to feed Mankind and render hunting and fishing as archaic unnecessary anachronistic practices.From the information laid out, most people acknowledge hunting and fishing are anachronistic. Immediate rewards are sought without regard to irrevocable damage imposed on global ecosystems.
\end{abstract}

Keywords:Anglers;Biomedical;Carnivores;Engineering;Food;Fishers;Hunters;Population;Psychology;Recreational;Retards;Sports;Vegetarian;Wildlife

\section{Introduction}

In a sense all engineering activity is a form of bio-medical engineering, in that most organized human activities taming nature or exploiting its' resources, impacts the well-being and health of lives of people, communities and nations. Wild hunting and fishing is an outdated form of free-for-all bio-medical engineering, when those hunters and fishers go stalking their prey with specialized tools. This may be regarded as the earliest form of bio-mechanical engineering to provide food. Accordingly a brief history of how humans procured food, some modern methods of food production, food supply, distribution and food economics, with a short comparison of vegetarian and carnivore diets, will clarify this appraisal.

\section{Provenance}

The wild hunting and fishing craze in North America has 'gone bananas' in Quebec Canada; over 280 hunters and 700000 anglers spend some Cdn $\$ 1.6$ billion each year pursuing their thrills. This creates many thousands of seasonal jobs, particularly in remote areas, lakes and forest resorts, (like Lake Iroquois Qc, and Seigneurie du Triton Qc, Pourvoirie Mekoos in Haute Laurentides, Qc and Pouvoirie Club Hosanna in Mauricie Qc) where wild life is prevalent [1]. Other places in Canada and the United States of America also condone fishing and hunting. Reasons for indulging in these recreational activities vary widely from psycho-therapeutic modalities (communing with Nature, allaying depression and calming down) to exhilarating thrills (adrenaline rush, honing of skills, personal challenges, and discipline sharpening), to exercising civil liberties and constitutional rights (the USA constitution allows citizens to bear arms for self-protection). Although each state or province has its own rules constraining these activities, the collective destruction to wild life is progressive, and inexorable irreversible planetary damage has become critically compelling.

\section{Aim}

This article appraises the global food supply and explains why there is no need for hunting and fishing in the $21^{\text {st }}$ century.

\section{History of human food supply}

Over millions of years ago Mankind evolved from arboreal ancestors to land-based hunter-gatherers. Humans were sparse and food sources were plentiful. Weather, seasonal changes and geography were the main determinants of supply, and diets varied according to rainfall, the annual seasonal changes and the zonal location of the people on the continents. Mankind's intelligence guided by astute observation and memory allowed for understanding the cyclical changes as to when trees, shrubs and plants would hibernate, flower and yield their bounty. Storage and spoilage was more problematic than harvesting in those times, and desiccation was among the earliest forms of food preservation. Cooking pickling and fermentation products followed. Roots, seed and plant products led to the establishment and cultivation of crops, with soil management and exploitation becoming part and parcel of the progress of civilization. Hunting animals, fishing, and 
gathering of wild growth foods was prevalent, and collectively they successfully supplemented sparse agriculture.

But as populations grew in size, and hunters and gatherers had to go further and further afield to procure nourishment, a change of nomadic lifestyles materialized. Small encampments became small villages and successful crop cultivation kept people close to home. Stored grasses and grains allowed for easy domestication of fowl and animal, which became a livestock source of dairy products, poultry and meat. Fresh food was produced daily and storage and spoilage were the main residual problems rooted in primitive farming, agricultural and animal husbandry practices. Salting, pickling and fermenting techniques were the main methods for food preservation until the mid nineteenth century. Cooked meats were kept in salty brine, or cooked and kept under thick layers of solidified animal lard. This did reduce, but did not eliminate, bacterial and fungal contamination and storage usually failed after a few months. Cooked food sealed in metal cans (with lead initially) was the start of the canning industry. Subsequent refinement of canning in metal, glass and plastic followed.

Cooking food usually sterilizes the contents: subsequent preserving, freezing, drying or granulating gives the food a longer shelf life. A whole industry of disinfected natural (fish, meat, vegetables, grains, cereals and fruits) and manufactured composition foods (corn- and wheat-products, sauces, condiments, pickled vegetables, mayonnaises, mustards, chutneys, jams, whole meal-mixes) were preserved for later consumption. Dehydration and smoking was limited; this enhanced flavor and prolonged shelf life of fish and meats, but keeping smoked products sealed and dry posed practical problems. For improved preservation and storage delicatessen foods used heat, smoking, gas storage and sealing methods to optimize shelf-life. Beverages like beers, wines cider and spirits were procured through fermentation and for centuries as these liquids, besides boiling water, were the only reliably safe source of fluid intake. The challenges faced by drinking natural raw water are discussed and deconstructed elsewhere [2-4].

The progression of techniques and the huge increase in understanding food pollution in the past two centuries (1800$>2000$ CE) from growth through harvesting, manufacture storage, marketing, processing, distribution and consumption, has vastly increased global production of food. The ways this was achieved warrants a closer look.

\section{Modern methods of increasing food production:}

A. Food production was strongly influenced byunderstanding the chemistry of agriculture. From ancient times till today, volcanic soil enriched from passed eruption ash flakes, was valued for its richness to grow wheat. Early Etruscan farmers prized poultry droppings for plentiful crop production as best, while other organic manures from donkeys, cows, goat, and sheep manures, less so. Modern analytical chemistry revealed the molecular elements inherent in these traditional sources of soil fertilization. A soil, with an abundance of plant nutrients, always yielded robust bumper crops [5]. This understanding led to the use of modern phosphate and nitrogen fertilizers, with all other needed trace elements like zinc, magnesium, potassium and others, to yield maximal crops.

High yields satisfied local demand and excess had to be put to good use. Also huge crops were vulnerable to arthropod infestation, spoilage and transport problems. The use of bio-degradable insecticides became prevalent, and exploitation of hot-house hydroponics and gene manipulation was introduced to control and augment desirable characteristics of produce. Irrigation and the drip system for moisture were perfected for enormous acreages of planting.

B. Post-harvest handling of foods is important. Exploitation of plant physiology for fresh fruit and vegetable and also for managing pulses and grains is important. Understanding the biochemistry of fish and seafood, red meat, dairy products and other plant and animal products, ensures minimize deterioration and wastage. A variety of engineering skills are employed for this.

Preservation using chemicals and prevalent microbes with fermentation, antimicrobials, antioxidants,, $\mathrm{pH}$ lowering (Acidifying) agents, and nitrides maybe used, Preservation may be achieved by reducing water structure and atmospheric modification with temperature, moisture; also with ultra-violate light, and, gas (like ethylene for ripening warehouse of bananas), osmotic dehydration, air-drying, surface treatments, coating encapsulating and membrane technology.

C. Physical heat and energy by putting energy in (heating), or taking energy out (freezing), preservation of foods is achieved. This embraces: Canning, pasteurization, sterilization by cooking, frying, freeze-melting (or freeze-concentration as with fruit juices for example), microwaves, ultrasound, ohmic heat, fridgeration, light, irradiation, pulsed electric fields, magnetic fields, and high atmospheric pressures. These techniques may be used individually or in combination to enhance delayed putrefaction.

D. Smoking is used from individual primitive smoke tins and boxes, to large industrial smoke houses for commercial production of smoked fish, meats and other delicatessen edibles. Burning wood gives unique flavors and leaves chemical residues which inhibits bacterial growth. Barbecuing with fossil fuels is spurned, as these smoke sources introduce carcinogenic nitrosamines and cyclic hydrocarbons into food [6,7].

E. Finally indirect methods which impact food quality and safety is the approaches used in the packaging(like oil infused individual paper wraps of fruit to delay simultaneous ripening), sanitary conditions of harvesting, transporting and preparing food. . Hazard analysis and Critical Control Points (HACCP) and Good Manufacturing Practices (GMP) devise principles which dictate acceptable successful hygienic practices for food delivery. These will embrace proper management from individual domestic consumers, to mass transport and deliveries of megatons of produce by rail, sea and air, to markets [8].

Increased demand for animal protein: To meet the increased demand for animal protein, domesticated animals which for 
centuries were free-roaming on farms, have now been housed in animal-battery farm-factories (ABFF). Poultry as chicken, turkey and duck farms exploit intense egg-laying with subsequent hatching and mass clutch raising techniques. Feeding is optimally ample to yield maximal protein growth while movement is minimized to conserve mass. Animal husbandry applies similar principles for pork and beef production. Biochemical manipulations using hormones (like diethyl-stilboestrol-DES) and antibiotics (like penicillin and macrolides) have been abused to increase bulking-up flesh yield and sales profit. These techniques have been moderated or banned (see disadvantages below), but the perfection of knowhow to improve meat production continues.

Consequently an abundant gross supply of affordable meat comes to global markets with greatly increased nutritional value to global populations. These ABFF's provide enough food for over 300 000000 (three hundred million) people in North America and their excess production is exported worldwide. The excess meat as beef pork and broiler poultry production in 2018 for export, from the USA alone was: Beef over 10500000 million Metric Tonnes (CWE/ RTC); Pork 8.25 MT and Broilers over 11million MT. This was an increase in exports of 5\% for beef, $2 \%$ for broiler meat and $1 \%$ for Pork, and is expected to rise $[9,10]$. This is important as this fact impacts strongly on the narrative presented below on fishing and hunting.

Major disadvantages arise from these principles is from crowding, animals grouped and housed into confined spaces, and it is labor intensive. Despite mechanization (as for example in milking), animal-battery-factory farms are prone to developing and transmitting diseases. Both viral (like Avian Bird Flu, Cowpox) and bacterial (like Salmonella and Listeriosis) infections are frequently implicated on ABFF's. Also prevalent are: weak bones (osteoporosis) in animals; decubital ulcers on caged animals, and most importantly the emergence of antibiotic-resistant-microbes (like methicillin resistant staphylococcus MRS). These antibiotic resistant microbes are often referred to as 'Superbugs', and may be fatal for human beings. Accordingly the use of antibiotics and hormones, in ABFF's, has produced serious human medical problems, and their use is subject to strict controls and is slowly being phased out. This mortality is minimized when meats are thoroughly cooked and not eaten raw. Consequently minced or ground meat should not be eaten underdone or rare, and steak-, or fish- 'tartar" always carries a risk of being infected.

Serious agricultural engineers have scrutinized these methods and continually strive to eliminate these disadvantages. Some states have banned farming-use of growth enhancing hormones and non-pathological use antibiotics, and modified improved farming methods are ongoing to improve animal welfare and to minimize disease, suffering, stress and abuse. Free-range raising of farm animals, and eschewing synthetic growth modifying chemicals has encouraged the growth of the 'Organic farming' movement, which uses 'natural chemicals' and endeavors to improve production methods with minimal use of synthetic chemical moderation. This movement relies on traditional methods (like using animal manure for fertilizers) but may not offer any significant improvement of produce. World-wide there is also a tendency for people to eat less meat and consume more fruits and vegetables.

The world's human population exploded exponentially after the Industrial revolution: the increase rose from 1 billion souls in 1800 to over 1.6 billion in 1900 . Increase in population growth was $2.09 \%$ in 1968. Dire predictions were made at the end of the $19^{\text {th }}$ century (1900) well into the first half of the $20^{\text {th }}$ century (1968 with over 3.5 billion), that by year 2000 , the world would be over populated, with little space for survivors; and they would all be scrambling and fighting over access to food supplies. The introduction in the 1950's of the female hormone based contraceptive pill had a significant effect on reproduction rates. Gratefully those pessimistic disastrous predictions of famine in general did not materialize, the yearly change decreased (from $2.09 \%$ in 1968 to $1.09 \%$ in 2018) and the world's population is currently 7.6 billion in 2018 [5,8].

For example, global farm output between 1820 and 1975 doubled four times. First doubling was between 1820 and 1920; second between 1920 and 1950; third between 1950 and 1965; and finally ( $4^{\text {th }}$ ) between 1965 and 1975 . Mechanization with tractors, planters, harvesters and adapted farm-barns and storage-silos were embraced by farming communities. Over the twentieth century, farm-worker numbers reduced drastically with this automation of work. In 1940 one farm-worker fed 11 civilian mouths; but with mechanization by 2002, each farm-hand generated enough food for 90 consumers! Nearly 1 out of 4 workers (about 24\%) in the USA were agricultural workers between World War I (1914-1918) and the Second World War (1939-1945). Yet by the turn of the century (2002) only 1.2 percent of workers were agriculturally employed [5]. In 1951 urban dwellers were 770, 000, 000, just 30\% of global populations. By 2018, urban dwellers are 4,186,975,000, 55\% of the world's population. These urban dwellers are in the main satisfactorily fed and agricultural output per farm worker has increased proportionally.

A. Manipulation of nature: Water retention for redistribution and use of potential energy to generate electricity has forced many nations to build hydro-electric dams. These civil hydro-electric constructs have interfered with natural fish migrations, spawning and breeding. Exploitation of natural geologically determined water-falls are successful, but diversion of more shallow 'whitewater' rapids often have unintended consequences. Advantages of a regular affordable and renewable energy resource compensate for these unintended consequences. Fish migration paths are altered and engineering alternate flowing waterways allow this natural phenomenon to be sustained. Fish farms alongside natural water ways amply compensate for reduced natural fish harvests, while allowing for cyclical spawning, but reduced, spawning and upstream fingerling growth. The impact of reduced fish migrations on much wildlife (like bears) may be reduced, but is not entirely eliminated. Downstream controlled water-flow of during drought periods may cause drying up of wetlands with loss of much water dependent fauna and flora; it allows for better irrigation management, water conservation and consistently increased crop 
yields. Yet poor planning, unpredictable climatic weather changes and unexpected flooding still allows for enormous water damage to crops, food production, transportation and domestic housing.

B. Mankind's drive to control nature: Huge agricultural holdings exploited insecticides and selective herbicides for decades. Mechanically engineered farm crops like wheat are wind pollinated and agricultural wheat production ruthlessly abused insecticides and herbicides. Mono-culture crop production spread worldwide and was driven by increased profit motives without regard to irrevocable destruction to existing ecosystems. Most adjacent wild flowers were wiped out and vast populations of insects too. This controlled crop infestation by killing off insects, and spoilage from unwanted plant growth labeled as 'weeds.' The unexpected result was less activity by crop boosting pollinating insects including imported bee-hives. The loss of wild flowers reduced the number of insects which in turn reduced the number of birds that relied on insects. Pollinating insects are responsible for most fruit-crops and vegetables consumed by Mankind. Beehive collapse and loss of wild pollinators have forced some areas to resort to hand-pollination during blossom periods to sustain fruit production. The loss of birdlife has left large areas without birds whose chirps are now replaced by silence in the mornings, the countryside and in spring.

The diminution of natural habitats has seriously impacted the survival of indigenous wild life in affected areas. The voracious demand for industrial, mining, agricultural and urban sprawl has inexorably reduced wild life habitats, like forests, woodland areas, water-ways, open fields and swamps. Species dependent on these environments are so reduced many face extinction. Wild life from large species [like tigers, elephant, leopard, buck large and small, to small rodents, aquatic species, birds and ducks], all are threatened with long-term extinction. Enough land has been expropriated and plundered for food production; proper use of these will easily maximize crops for food productions with optimal management. Creeping desertification, dykes, dams, loss of wetlands, water drainages and irrigation schemes all may threaten wildlife by disrupting or usurping natural environment ecologies. Added to this mismanagement of resources and wanton slaughter wrought by hunting, the future damage to earth's natural resources is dire.

C. Dragnet-fishing and trawling: For centuries the sea was regarded as an inexhaustible source of marine resources. From fishing, whaling, sea weed collection and crustacean harvests, billions of tons of marine food was taken from the wild oceans and fed multiple generations of humans. This was possible over a stretched period when the enormous oceans could recover and replenish seeding stocks faster than mankind could plunder resources.

D. Fish farms: Marine biology is now exploited globally as fish farms and marine food colonies. Using modern scientific aquaculture apparatus and techniques, one adult female fertile fish and one mature matched male can supply enough fertilized spawn to fill a fish-farm dam. Fish-food is mainly plant based and manufactured in bulk-pellets which farmed fish voraciously consume. The waters temperature acidity and microbial biomes are monitored and controlled, keeping it parasite free, and the fish fed food which is successfully transformed into "first-class-piscatorial protein". To minimize waste and maximize protein conversion by the fish, the fish are harvested, gutted and cleaned, and the offal is recycled into the fish-food pellets, while the flesh is sent off to markets. All varieties of fish farms exist. Fish metabolism demands energy and fish-farms are also built in deserts, where warm temperatures allow for less energy needed by fish, and resultant greater bulking up of body protein.

a) Salmon fish [Many species including: Cohoe, Chum, Chinook, Humpback, Euro-Atlantic, Sockeye] are spawned and raised in controlled waters. These fish farms have proliferated in the past and are a major source of protein for North America, Europe and Asia.

b) Wild lobster and crab oceanic water-beds are seeded with spawn and both lobster and crabs, which must reach a minimal size to be retained in catches. Harvesting of these resources are sea-going and labor intensive and still demand specialized boats and crew. These ventures are not without physical risk but produce high quality protein foods and are highly profitable.

c) Oyster, mussel, and clam floater-farms: These aquaculture enterprises are littoral floating industries which often have successfully replaced abandoned fishing towns and villages where wild fishing as a livelihood has diminished to unsustainable levels. Floating islands are launched and growth of the mollusks strictly controlled. Workers must sustain high sanitary practices as the harvests may transmit pathogenic bacteria (like Salmonella) from infected workers.

d) Prawns, frogs and snails: These foods are considered delicacies and demand for them has increased in recent years. A whole new variety of projects have been re-invigorated and with a mix of success and moderated disappointment. This is because these endeavors demand more specialized advanced aquaculture knowledge, unpolluted water estuaries, rivers or dams. For those who master these cultivating and harvesting skills, the overall rewards are enormous.

More consumable first class protein will soon originate from aquatic, riverine, estuaries and marine engineered farming enterprises than those from wild-hunt-and- catch oceanic sea adventures.

Genetic Modification (GM): GM foods have made a major contribution to healthy global nutrition by enhancing crop quantities and biochemical properties of cultivated foods. Every living organism has its' own genetic code. Modifying the genotype may occur slowly and naturally through serendipitous genetic mutation, and over millennia and seed selection many contemporary foods are consumed today, in spite of having poisonous ancestors; the common tomato and almond nut are two typical examples. Most commonly consumed fruits and vegetable consumed in the $21^{\text {st }}$ century are products of selection for propagation of genetically modified mutants. Genetic manipulation allows for resistance to plant infections, parasites and drought, and also improves color, size, 
shelf-life and nutritional value. Modified wheat and rice can include synthesis of selected amino acids. Genetic modification techniques have been simplified (like using CRISP to insert desirable genes) and also successfully commercialized by international agricultural marketing firms, like Monsanto. The remote possibility exists that certain GM foods may be harmful to health. This has never been shown to be a scientifically substantiated concern, although some people may blame allergies to specific foods regardless of whether they are GM or not [11]. See below comments on cell cultures.

A. Transporting food: Mass harvesting, transport and shipping of food, presents unique challenges. Refrigerated trucks, giant gas (often nitrogen) soaked skips, and other specialized sealed containers have facilitated moving perishable food over long distances. Grain-hop container-ships facilitate bulk exports of grains and cereals like wheat, maize and rice between international destination ports. Distances between production sources and abattoirs for meat are reduced, sometimes having meat factories adjacent to the ABFF's. Livestock now have specialized ocean-going ships which can move thousands of live animals from countries of origin to consumer cities for slaughter, as for example moving quality steers from Australia to Saudi Arabia. Generally slaughtering is quick, painless and stress free. Religious rites of slaughter (Halal/ Kosher) are respected, observed and implemented whenever possible. The vast majority of slaughtered meats are consumed fresh, but a huge quantity is processed for delicatessen by cooking, spicing and smoking which allows for longer storage times and consequent facilitating transporting to distant destinations.

B. Finance and supply management: Globally production of food is a for-profit enterprise. Agricultural engineering has reflected the genius of Mankind over millennia and spectacular harvests have yielded spectacular profits. Worldwide food production rewards handlers at every level with financial benefit. Profit proportions vary and the fewer 'middle-men' that are needed, the more the profit can accrue to farmers and producers. Also at the production level, assuming good acceptable quality of produce is sustained, the greater the size of a crop harvested, the bigger are the financial profits. Farmers Co-ops, workers unions, importers, exporters and distribution cartels all endeavor to divide up the profits with maximum benefits; there is much room for improvement and innovative checks and balances are ongoing as needed at all stages, continuous. Because dairies work every day and cows produce daily milk, production of dairy products frequently may exceed consumption rates. Accordingly basic economics of supply-anddemand must be managed to ensure there is no waste, and that dairy farms, farmers and animals thrive and survive. But generally, food distribution is successful and has improved enormously during the $20^{\text {th }}$ Century. Over production of food, which may be difficult and expensive to store, often has to be controlled.

Vegetarian versus carnivore: Sound nutrition demands a balanced dietary intake of energy food, consisting of fats, carbohydrates, proteins, vitamins, trace elements, roughage and water. These sources allows for a wide variation of choice and geography, climate, resources, cultural practices, social distribution as infrastructure and personal available income all affect dietary selection quantity and quality of global diets. Health benefits accrue to vegetarians more than meat eaters. Besides liquid and sources of calories, there are groups of metabolites which must be ingested by Mankind. Human metabolism uses these sources for metabolic and catabolic functions in health. Both vegetarian and meat inclusive diets are prevalent world-wide, with the vast majority of the planets population being vegetarians. A short summary of these are pertinent for the theme of this narrative.

These include mainly:

A. Amino acids [a.a.], are the building units of protein. The known amino acids are arginine, cystine, histidine, isoleucine, leucine, lysine, methionine, phenyl alinine, threonine, tryptophan, tyrosine, valine, alinine, aspartic acid, glutamic acid, glycine, taurine, proline and serine. Nine of these which are components of the body proteins are deemed essential constituents of the diet. The essential a.a's are histidine, isoleucine, leucine, lysine, methionine, cysteine, phenylalinine, tyrosine, threonine, tryptophan and valine. They are found in animal and vegetarian foods. 'First class' protein is usually and easily resourced in animal protein like meat, fish and dairy products. Immature metabolism in infants cannot convert Methionine into Cysteine and Taurine, and these two a.a.'s are deemed essential for infants. Methionine (S-containing) may be compensated for by Cystine (also a S-containing a.a.) and Tyrosine, which can convert to Phenylalinine.

B. Vegetarian sources of a.a.'s. Many vegetables like pulses (including beans, peas, lentils, chickpeas sorghum, kinwah, GM modified rice, maize, wheat and other crops) contain selected essential amino acids. For adequate metabolism for human protein to be synthesized for health, plant based essential amino acids should be ingested, preferably simultaneously in one meal. All essential a.a's are prevalent in vegetables like pulses and grains. Beans, peas, lentils and nuts contain methionine, tryptophan, threonine, isoleucine, lysine, and leucine. Consumed in combination, they provide these a.a.'s and facilitate optimal protein synthesis and metabolism in vegans. Traditional vegetarian diets are not deficient in these a.a.'s, and whole populations (like Hindus and Buddhists, and Taoists), eschew all animal based protein, embrace veganism and thrive and survive exclusively on vegetarian foods.

C. Fats are constituted by fatty acids and glycerol. Some fatty acids (like linoleic and linolenic) are pre-requisites for healthy neural development and function. Saturated fats from mammalian animals are causally associated with human vascular disease. Unsaturated fatty acids from plant sources, like olive, canola and avocado oils, and fish oils are more easily metabolized by humans and are less frequently implicated in vascular pathologies. Fats yield high calories and provide heightened taste to foods. Excess production of animal fats (like those from sheep, pigs and beef) are diverted to soap factories; sodium hydroxide is combined with these fats to industrially manufacture detergents and soap products.

D. Vitamins are of two types: Oil soluble (and Vitamins-A, D, E and K) and others. (like Vitamin-B complex and Vitamin-C), 
although used in metabolism in small amounts, they are all necessary for sustenance of a healthy body. Vit-A is sourced in carotene rich foods and fish oils; Vit-D is also obtained from fish oils and is synthesized in the skin by sunshine drenched with Ultraviolet light. Vit-E and Vit-K are in many green leafy vegetable. Vit- $\mathrm{C}$ is essential and found in most fresh fruits and vegetables. Vit-B Complex (Vit B complex includes thiamine, riboflavin, niacin, Vit B1, Folic Acid, Vit B12, Pantothenic acid, and biotin). All vitamins plat a specific role in metabolism and adequate intake is essential for sustained health. A varied diet ensures adequate intake of all these vitamins, but diets deficient in any vitamin will manifest pathological signs and symptoms. Anemias become prevalent in diets deficient in Vit-B12; scurvy may manifest with prolonged dietary deficiency of Vit-C. World-wide a whole industry has been engineered that provides all vitamins to international markets and populations. Globally the spread of knowledge and supplements of vitamins has been so successful, avitaminosis (metabolic disorders arising from lack of a vitamin) is rarely encountered in the $21^{\text {st }}$ century.

a) Trace elements: Many other elements are included in a healthy diet. These elements include Calcium, Sodium, Potassium, Manganese, Chromium, Molybdenum, Cobalt, Vanadium, Nickel, Silicon and Tin, Selenium, Fluoride, Sulfur, Iodine, Iron, Copper, Magnesium, and Gold. These are inherent in a mixed diet, and even though national cultural culinary methods, tastes, and selection of foods vary, different diets adequately provide all these nutrients.

b) Cell cultures: Biomedical techniques have successfully grown cells in laboratories, and cell lines can easily be manipulated with genetic skills (like CRISP). This allows all living cells to obtain and retain characteristic changes which mimic conventional foods. Growing cells to emulate ground beef can yield a clump of cells that when cooked, cannot be differentiated from the real thing. Nutritionally they are exact copies of meat. Vegetarian substitutes are also produced and supplement a whole range of 'Tofu' (bean curd) protein products, which provide essential amino acids for a diet.

c) Genetic engineering: Natural selection, selective breeding and artificial insemination of livestock have enabled procuring of animals and poultry with desirable phenotype traits and physical qualities for food. This is a form of genetic engineering and most meat farmers have the necessary knowledge and skill to produce optimal animal herds and flocks for human sustenance. The global beef, pork and poultry production has expanded multiplied in the last century and adequately meets the world-wide need for fresh meat.

\section{Fishing and hunting: is it pillaging and killing?}

A. Thesis: From the information laid out above, most informed people will acknowledge that hunting and fishing are anachronistic practices. Immediate financial (and with wild hunting an emotional psychological) rewards are sought without regard to irrevocable planetary damage imposed onto global supporting ecosystems.
B. For example: Hunting and killing elephants for their ivory tusks. Elephant populations in Africa and Asia have been decimated by hunters who kill them for the ivory profits. Wild deer killing for trophy hunters promotes that the largest specimen killed, the greater size of the prize, and the greater is the ego-trip pumped up for the hunter. Hunters always want to bag "The Big One!" as a trophy. This is a spurious long-term goal, in that mature specimens are the best breeders in the wild and are necessary for quality gene-selection of species replacement in the wild. Collectively big animals will stop passing on their genes and only genetic runts will be left.

C. Another example: Use explosives to catch fish; exothermic implosions (like use of dynamite) stun fish with consequent destruction of subjacent coral reefs and their associated marine biodiversity. This permits an easy grab for barrels and nets to be filled with floating stunned or dead fish [10]. Factory fish ships trawling the seas, mechanically haul in huge dragnets with tons of marine wild life with. Besides the major type of fish captured, an excess of by-catch among dominant species is destroyed. For example herring or sardine shoals will include a wide array of other fish that feed on the shoals. Shark fishing is done by killing and massacring sharks for their fins alone (to make shark-fin soup), the rest of the sharks body is discarded.

A further example is the wild whaling fishing industry. Whales were ruthlessly hunted for centuries. Mechanically engineered whaling factory ships perfected technology from harpooning to hauling carcasses on board for processing. Daring adventurous hunting of occasional individual whales was replaced by a whaling industry that depleted whale stocks to the brink of extinction. Hunting for whales was exploited for monetary gain, and eventually banned when governments, financiers and marine biologists realized continuation of the residual whaling was no longer profitable, not sustainable and would kill all whales into extinction. Although the entire whale carcass was used (for food, oil, bonemeal or ambergris), abundant alternative cheaper resources, both natural and synthetic, have successfully replaced whales as raw material. A world-wide ban wild whale hunting is operative $\left(21^{\text {st }}\right.$ century) and marine whale populations are slowly recovering.

Wildlife on land, in the sea or air has no hope of outsmarting or avoiding being targets caught in Mankind's industrially engineered killing traps.

\section{Discussion}

There is still anxiety about food security as a growing concern worldwide. By 2050, some bio-engineers predict there will be nine billion people to feed, and that climate change will be strongly and negatively impact agriculture. Nearly one-third of food produced globally for Mankind is wasted. Also nearly over 30 percent of crops worldwide are lost annually to weather, pests, infestations, plant disease and other factors before they are harvested. Clearly there is much room and opportunities for engineers to salvage and markedly ameliorate this situation. In spite of this wastage, the world in 2018 still produces enough food from agriculture and animal farming to 
feed everyone globally. Globally most of Mankind survives well on a vegetarian diet, and the meat, fish and dairy industries produce an oversupply of protein for omnivores and human carnivores.

\section{Transport}

Most problems of distribution arise at the final destination; in less developed countries rail and road transport to where the food is destined may be inadequate and often food is clogged up in warehouses because distribution is slow. But the methods of food preservation, transport and distribution in the main have been solved.

Wild-hunt-and-catch, free-for-all marine adventures, [in spite of restrictive legislating controls by shore-bound countries over traditional fishing grounds], have depleted piscine seeding stocks and damaged natural marine ecosystems. For example cod fishing in Atlantic Canada was nearly wiped out from over-fishing. Commercial fishing has become a risky and diminishing returnon-capital investment business as more and more consumable first class protein originates from aquatic, riverine and marine enterprises, than those from wild-hunt-and-catch, free-for-all marine adventures. Ruthlessly hunting and killing wild animals is sustained as a business for fun excitement and amusement, not as a supply of meat. Domesticated animal husbandry more than oversupplies global demand for meat.

In evolutionary terms, Mankind's ancestors were [until relatively recently], mainly vegetarians. Climate change shaped human evolution. Between 2.7 million [Australopethecis africanus and $A$. aferensis] and 1.2 million years ago [Homo neanderthalensis as Homo naledi, H. habilis, and H. erectus], as mankind, humans changed their diets by being an ecological generalist with an increasingly flexible diet feeding on the available biospheric buffet. Paleontological evidence, from animal bones, skulls, flint instruments with associated rocks and soil sediments, all indicate that Paranthropus robustus and P. boisei and those in the Homo genus, were omnivorous and ate meat [12-16]. Hunting stone tools, arrow and spear heads and specialized foodprints on fossilized teeth confirm this. The major attitude evolving from this is that people only hunt animals for food. This is patently false, as in contemporary $\left(21^{\text {st }}\right.$ century $)$ times, most hunters are exceptionally well-fed, and hunt for re-affirmation of personal dominance, bragging-rights and emotional empowerment. Hunting from abundant herds of deer, buffalo and other wild ungulates was a good renewable resource for animal protein in ancient eras, until avarice, abuse of bullet-gunfire intensity, blind stupidity from over-hunting so reduced animal herds, they could not recover. The North American buffalo, which numbered in the millions in 1800 , by 1930 were placed on the endangered species list.

After emerging from arboreal forests, Mankind changed from nomadic lifestyles to established towns, made people vulnerable to attack theft and plundering for accumulated reserves and resources. This fostered enmity, jealousy and coveting between tribes, and sectarian warmongering became prevalent. During The Middle Ages, when the Roman Empire disintegrated, Europe held some 500 principalities that were at constant strife with each other. This evolved into National confrontations, which were driven by greed, ideology and food availability.

The First World War (1914-18) was a culmination of confrontation of interests based on, self-promotion, insatiable dominance, economics, empire building, colonialism, nationalism and imperialism. After 1918 there were as few as 35 Euro-national entities and post The Second World War (1939-1945), this number reduced further. Subsequent to the USA-Russian Cold War 19471985 , and into the $21^{\text {st }}$ Century, a unitary European Union emerged. With the exception of the Far East (Viet Nam, Korea, Pol-pot Cambodia and Malaysia) and the Middle East (Irak, Syria, Lebanon, Libya and Israel), ongoing belligerent physical destruction from wars in Europe, North and South America, and large areas in Africa, Asia and Australia were reduced. War mongering has reduced significantly compared to previous centuries, and many national hostile emotional forces are now re-directed and diluted into local, regional and international sporting jousts. This relative peaceful co-existence allowed land and aquatic industrial farming-engineers compelling unique opportunities to design and implement systems which produce maximum quantities of good quality food. There was enlightenment with informed, progressive growth of successful food production, and in the late $20^{\text {th }}$ century and now in early $21^{\text {st }}$ century; the world emerged from the Dark Ages of food shortage and famine, into a global cornucopia of oversupply of food.

Angling as 'sport' is a small fraction of what commercial fishing boats take from raping and reaping waterways of schools of fish with dragnets and trawlers. Anglers always chase "The Big One!" This is often a futile long-term mission, in that mature fish are the best breeders in the wild and are important in ensuring populating lakes and rivers with fish. There is no need to fish for food any more, but anglers catch-and-release policies have allowed wild-life fish resources in rivers and dams to survive. Fish farms and marine estuaries seeding and harvesting sea-food yield renewable crops of fish protein in variety and abundance to satisfy international needs.

Changing mindsets on hunting and fishing: This is a challenging task and it takes time to change people's attitudes, values and thinking. Convincing people with fixed attitudes, that hunting and fishing wild-life will irrevocably damage the planet, and will drive all land and marine animals into extinction, demands changing a mindset of embedded cognitive prejudices. Many approaches are possible, but defining some major hurdles could help. 1) Most people are not interested in educating themselves out of ignorance. When short of time, with many intrusive influences impacting their lives, people rely on simplistic thought processes, trust available experts or accept shortcuts from group consensus. 2) Making judgment calls on knowledge is conflicted because people tend to 'Cherry-pick' from presented information, those facts which are in concordance with their own biases. Most people have an automatic tendency to focus on supporting aspects over others, and to interpret voluminous evidence that conforms to their own pre-existing beliefs. 3) Potent prevalent social attitudes strongly influence assessment of facts. The wish to conform to the views of a 
dominant group, the desire for improved social status or enhanced attractiveness for a mate, all impact taking a decision and acting on it. Social psychology provides ways of coping with heuristics, confirmation of biases and social pressures. When communicating accumulated facts about hunting and fishing, switching away from heuristic impulses demands a rational systematic approach which permits improved general evaluation. Challenging hunters and fishers to examine their personal biases, and to make a case for and against their values, encourages them to examine the evidence and provenance of food supplies. Often new evidence is given more weight and their biases are moderated. Social pressures derive from consensual validation; yet a single disagreeing person could evoke strong discussions with consequent consensus breakdown. Conformity tends to emerge from fear, and skeptics will always argue vehemently. To convince them to embrace more modern scientifically supported facts, their arguments should be classified and typed as heuristic, biased or products of social pressure $[17,18]$. This way the thinking about hunting and fishing could make for change, and come to be regarded for what it is killing of wild animals and pillaging sea fish stocks.

\section{Concluding remarks}

The world-wide female hormone-based birth-control pill was successfully introduced in 1955 (world population over 2,7 billion and 1,76\% annual increase), and together with increased agricultural production, these are now understood to be fundamental collective factors, that ensures a Man-made global famine and international humanitarian crisis will not materialize. The imbalance between population growth and food production has been reversed.

Yet with industrialized mechanization of the whole marine biology businesses, the oceans no longer can withstand this endless plundering and destruction. Not only has ocean abuse materialized from polluting plastics (synthetics like poly-propylene and polyethylene), human wastes and garbage (sewage and city trash) have so fouled the seas, and overfishing (with drag-nets, kilometers of trawling-lines, fish factories at sea) with abuse of scientific knowledge (like dynamiting schools of fish, deep-sea netting of ruffies) and ruthless killing of species (like sharks for fins, turtles for feet, seal-pups for fur) there is now a slow progressive permanent destruction of Natures' marine biodiversity and resilience. Marine resourcefulness is being irreparably damaged.

\section{Conclusion}

In the $21^{\text {st }}$ century, all too often exploitation of scientific knowledge and misguided engineering practices are used by biological morons and scientific retards for short term gain ignoring the long-term pain. Mankind's bloodlust for fishing and hunting is an anachronistic vacuous cruel motivator and activity. The bulk production of food is amply satisfied through worldwide, industrial, agriculturally engineered fabrication of food. The bloodlust for fishing and hunting has been quenched by Industrial agricultural engineering. Globally, wild-life hunting and wildoceanic fishing should be banned.

\section{References}

1. Elie C (2018) Into the wild. CAA Quebec 2018: 8-10.

2. Rasmusin WD, Nait K, Fussell GE, Mellanby K (2018) Origins of agriculture.

3. New world Encyclopedia (2018) History of agriculture.

4. Touyz LZG (2018) Water and exopolymers. Nature's biofilms and synthetic plastics. J Research Medical and Engineering 5(3): 1-9.

5. Scully M (2003) Food supplies and population growth. Influencing factors.

6. Kocak D, Ozel MZ, Gogus F (2012) Determination of volatile nitrosamines in grilled lamb and vegetables using comprehensive gas chromatography-nitrogen luminescence detection. Food chem 35(4): $2215-2220$

7. Thorkelsson G (1989) The effect of processing on the content of polycyclic aromatic hydrocarbons and volatile $\mathrm{N}$-nitrosamines in cured and smoked meat. Bibl Nutr Dieta 1989(43): 188-198.

8. Rahman MS (2007) Handbook of food preservation, $2^{\text {nd }}$ edn.

9. World Meters (2018) World population by year.

10. (2018) Livestock and poultry: World markets and trade. USA Department Agriculture.

11. Touyz LZG (2013) Genetically modified foods, cancer and diet; myths and reality. Curr Oncol 20(2): 59-61.

12. Kornei K (2018) Fish bombs. Sci Amer 319(1): 18.

13. Ungar PS (2008) Dental microwear and diet of the plio-pleistocene hominins paranthropus boisei. PLoS One 3(4): e2044.

14. Ungar PS, Sponheimer M (2011) The diet of early hominins. Science 334(6053): 190-193.

15. El Zaatari S (2011) Neandertal versus modern human dietary responses to climatic fluctuatios. PLoS One 11(4): e0153277.

16. Ungar PS (2018) The real paleo diet. Sci Amer 319(1): 44-49.

17. Kenrick DT, Cohen AB, Neuberg SL, Cialdini RB (2018) The anti-science thinking. Sci Amer 319(1): 37-41.

18. Hornsey MJ, Fielding KS (2017) Motivated rejection of science. American Psychologist 72(5): 459-473. 
(c) (i) Creative Commons Attribution 4.0 International License

For possible submissions Click Here

Submit Article

$\begin{array}{ll}\text { RMES } & \begin{array}{l}\text { Researchin } \\ \text { Medicil\& } \\ \text { Engieering } \\ \text { Sciences }\end{array} \\ \text { Benefits of Publishing with us }\end{array}$

